\section{Gingival Myiasis Affecting an Alzheimer Patient}

Sir,

Gingival myiasis occurs following direct infestation of oral tissues with the eggs of the flies which fed on the host's dead or living tissue, liquid body substance or ingested foods. ${ }^{1,2}$ The larvae of the species rarely involves the oral cavity. ${ }^{2}$ Predisposing factors include poor oral hygiene, presence of periodontal pocket, open bite in the anterior region, mouth breathing, ulcerative lesion and carcinoma. ${ }^{3}$ Most of the affected patients are mentally retarded, senile, immune-compromised, alcoholics, and living in poor conditions. ${ }^{4}$ To our knowledge, no reports are available describing gingival myiasis in an Alzheimer's patient.

A 67-year female patient reported to the Department of Dentistry, Rajendra Institute of Medical Sciences, Ranchi, India. Her relatives described the presence of live maggots in her mouth. The patient was previously admitted at Central Institute of Psychiatry, Ranchi as she was diagnosed with Alzheimer disease. The patient had symptoms of delirium, dementia, psychosis, and memory loss. The patient was unable to carry out daily routine activities, non-responsive to verbal communication and had been bedridden for many years. Intraoral examination revealed necrotic and edematous maxillary anterior gingiva with exposure of underlying maxillary bone extending from right side canine to left side premolar region. The patient had advanced periodontal disease showing recession, pocket formation, mobility, and halitosis. Live maggots were present deep in the periodontium and tunnelling in to nasal cavity (Figure 1). The maggots were white in colour, spiral form and size of about $5-10 \mathrm{~mm}$. A radiographic examination was not possible due to lack of patient cooperation. Gingival myiasis was the diagnosis.

Scaling and root planning was done prior to surgery. Under local anaesthesia, a periodontal flap was raised, and the wound was irrigated with turpentine oil and saline, debrided and sutured. Around 18-20 maggots were removed from the affected site with a blunt instrument. Supportive antibiotics and analgesics were prescribed; and the patient was instructed to come back after one week for review when the sutures were removed. The patient was followed up for a period of one month which showed restoration of healthy periodontium. The maggots removed were sent to the Department of Parasitology. The larvae belonged to Chrysomya bezziana, from the Calliphoridae family and suborder Cyclorrhapha.

Mentally handicapped patients are more susceptible due to inability to maintain proper oral hygiene and to ward

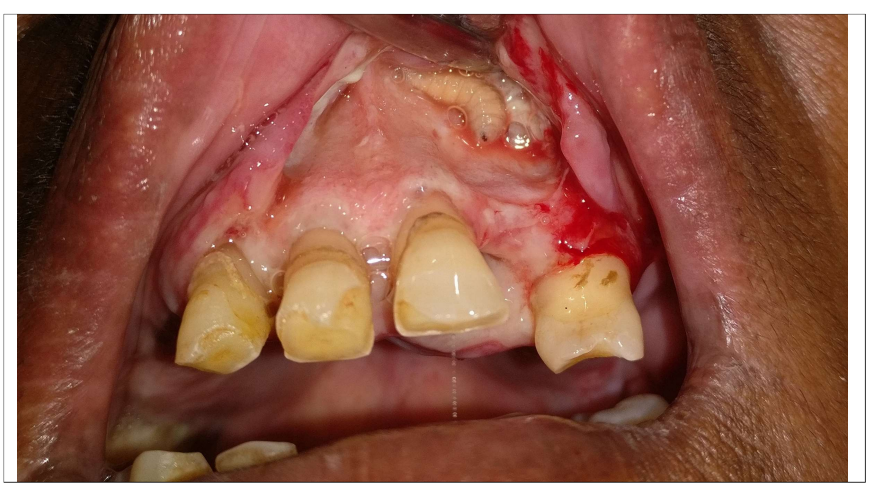

Figure 1: Clinical picture showing maggots burrowing deep into the periodontal tissue causing necrosis of surrounding soft tissue and exposing alveolar bone.

off flies inhabiting the oral cavity. This could have caused the eggs to be deposited inside the periodontal pocket. The moist, warm environment facilitated the hatching of these eggs and the maggots were protected by the confines of the pocket. ${ }^{3}$ The larvae penetrated deep into the gingival tissue resulting in separation of the mucoperiosteum from the bone and localised soft tissue destruction. ${ }^{2}$ Removal of the maggots was the most prudent treatment to prevent further tissue damage and bacterial infection. ${ }^{4}$ Similar treatment, as for this case, has been suggested by other authors as well.2,3

The case represented here highlights the importance of maintenance of oral hygiene in mentally handicapped geriatric patients. Medical personnel need to take special care, especially towards oral health for patients who are non-ambulatory and handicapped.

\section{REFERENCES}

1. Kumar SL, Manuel S, John TV, Sivan MP. Extensive gingival myiasis - diagnosis, treatment, and prevention. J Oral Maxillofac Pathol 2011; 15:340-3.

2. Günbay $S$, Biçakçi N, Canda T, Canda $S$. A case of myiasis gingiva. J Periodontol 1995; 66:892-5.

3. Avula JK, Avula H, Arora N, Manchukonda UK, Vivekavardhan Reddy N. Orofacial myiasis of the gingiva and nasal cavity: A report of two cases and general review. J Periodontol 2011; 82:1383-8.

4. Ribeiro MC, Pepato Ade O, De Matos FP, Sverzut CE, Abrahão AA, Trivellato AE. Oral myiasis in an elderly patient. Gerodontology 2012; 29:e1136-9.

Sonia Nath ${ }^{1}$ and Shaju Jacob Pulikkotil ${ }^{2}$

1 Department of Dentistry, Dental Institute, Rajendra Institute of Medical Sciences, Ranchi, India

2 Department of Restorative Dentistry, School of Dentistry, International Medical University, Kuala Lumpur, Malaysia

Correspondence: Dr. Sonia Nath, Dental Institute, Rajendra Institute of Medical Sciences, Bariatu, Ranchi, 834009 India E-mail: sonianath_12@yahoo.co.in

Received: March 09, 2018; Accepted: October 24, 2018

$$
\text { .......... }
$$

